\title{
Gap Analysis in Human Resources Allocation
}

\author{
Danyal Ahmed Subzwari Sayed Fayaz Ahmad \\ Institute of Business Management, Pakistan
}

\begin{abstract}
Gap Analysis is a significant technique to monitor and improve the services and performances in ongoing project. When it comes to Human Resource Management, gap analysis plays a key role in describing the individual efforts and work done of each and every participants of a particular project. This paper elaborates the significance, problems and optimizations of Gap Analysis in project management. Taking human resource management under consideration, analysis is made by measuring current allocation and future goals. Moreover, the precautionary steps is discussed in minimizing the gap analysis and making project management more efficient. Using proposed idea of Blind Dummy Task for reduction of gap analysis.
\end{abstract}

Keywords: Project management, Gap Analysis, Human Resource Allocation.

DOI: $10.7176 / \mathrm{JRDM} / 56-04$

Publication date: June $30^{\text {th }} 2019$

\section{Introduction:}

Project management is a name of temporary endeavor undertaken to create a unique product, service or result (PMI 2013). In modern day of business and technology, project management is an essential to create a unique output or services to reach the respective major objectives. Project is executed in 5 phases as mentioned below in figure 1. Planning and Execution are the important phases that should be properly monitored. Most of the hurdles and uncertainty exist in these two phases. Improper planning may lead to inefficient execution and inefficient execution may not achieve what is exactly planned.

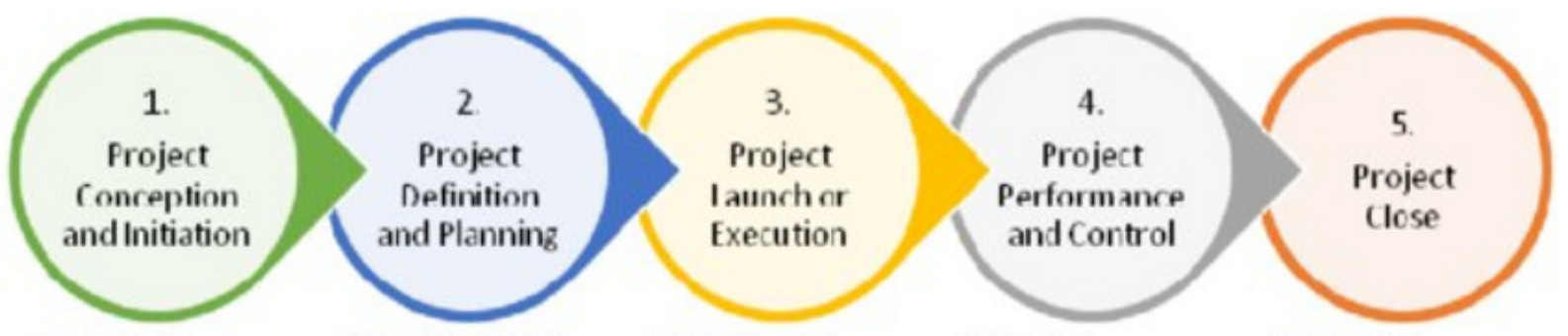

Figure 1- Phases of Project Management

When it comes to Human Resource Management, the improper allocation may results in waste of cost for acquiring extra man power or results in lack of resources. Other factors can be inefficient utilization, unskilled resources, environmental flaws and other unknown uncertainties. Such corrosive factor may lead to lack of sustainability in any ongoing projects.

\section{Literature Review:}

\subsection{Sustainability in Project Management}

Sustainability is significant approach to maintain the quality of process and output in project management. It can be figured out in various departments of Project Management. In academic literature review, the consideration of sustainability must be incorporated with well written document. It is applicable for long-term evolution in a three basic dimensions 1) Social 2) economic and 3) ecological (Økland 2015). The sustainability is defined as "The continuation of benefits from a development intervention after major development assistance has been completed. The probability of continued long-term benefits. The resilience to risk of the net benefit flows over time"(OECD/DAC 2002).

Sustainability is necessary top-down approach in which the strategic relationships between vision, mission and objectives. Several frameworks have been developed to acquire holistic approach for project evaluation and management (Freeman 2015).

\subsection{Human Resource Allocation}

One of the most significant and crucial part of project management is allocation of human resource. It lies within the framework of Project Management Triangle i.e the ratio between cost, time and quality) (Hendriks, Voeten, and Kroep, 2002). Implementation of correct algorithms will achieve the better efficiency target. For this purpose, the term Work Breakdown Structure (WBS) is strategically planned (Cobb, 2014). Work Breakdown Structure distributes the Human resource into different department hierarch ally which may result in better efficiency of services and outcomes. The allocation can be monitored by maintaining a written data and graph of 
Actual outcomes against Expected outcomes that is known as "Gap Analysis". The Gap Analysis not only used in Human Resource but also applicable in other fields of Project Management such as Cost, Quality, Procurement, Time, Scope, Communication and Risk.

\subsection{Design of Gap Analysis}

For monitoring and controlling the efficiency of Human Resource Allocation, there should be a statistical view and analysis that not provide measured records but also kept up to date (Ridder and Baluch, 2017). A gap analysis is defined as the comparison of actual value with expected value (Lee, 2017). It is obvious that gap analysis is included in the controlling phase of five process. The data and information has been extracted from planning and results in executions.

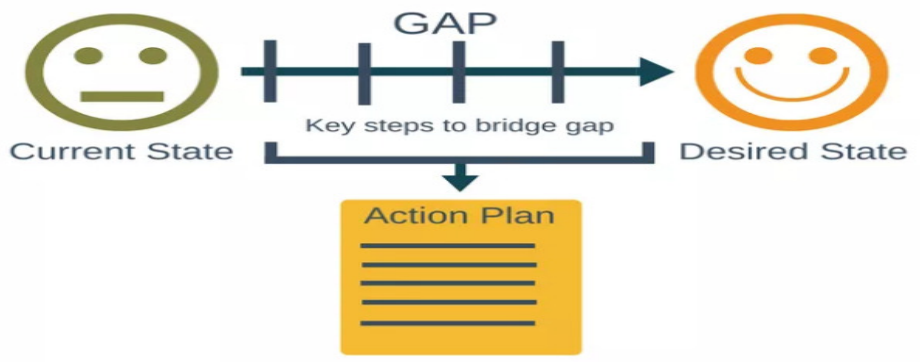

Figure 2: Schematic of Gap Analysis

Figure 2 illustrates the basic concept of gap analysis between current state and desired state. In the gap, the identification of action plan is created for implementation. Thus, it decreases the gap to provide better efficiency. Human Allocations, according to individual considerations and skills, has been scheduled. The skills and previous records inputs the date in a desired state covering up all the links with costing and quality.

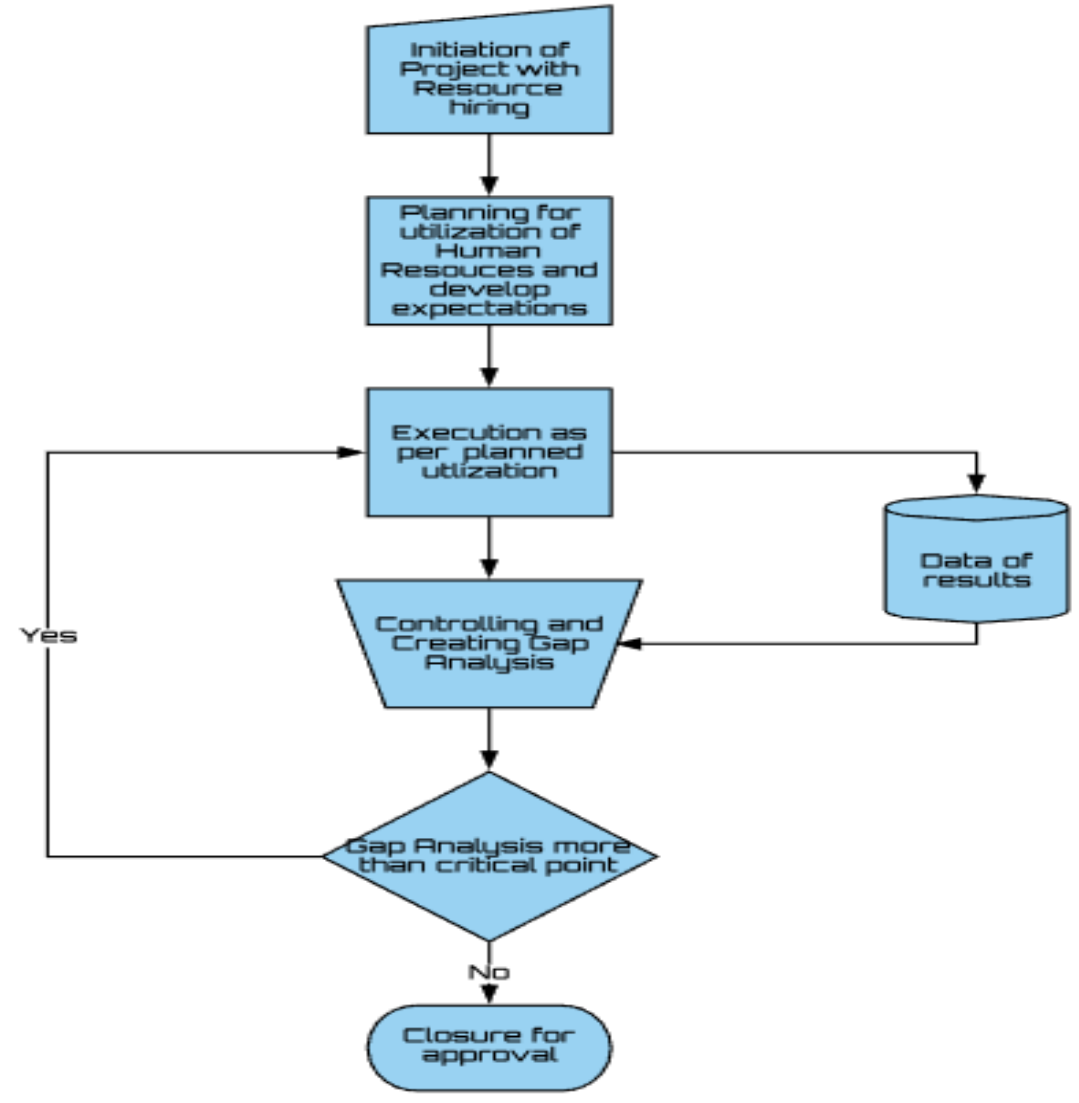

Figure 3 Design Flow Chart of Gap Analysis in Human Resource

Flow diagram in figure 3 describes the procedure of fetching gap analysis in the project. Resources are identified as a part of this project in initiation phase with scope baseline. Planning stage delivers the data for desired stage by reviewing the capabilities, skills, recent achievements and qualifications of every individuals from WBS. The desired stage help us to compare the actual outcomes by the individual. Execution has done as per planned allocation and delivers resultants to the controlling stage where the gap analysis will be calculated. 
The difference in outcomes, deliverable and duration will be integrated as gap analysis with respect to Human Resource Allocation and determines the efficiency of it in the project.

\subsection{Relationship with knowledge areas}

Project Management deals with 10 knowledge areas in which obviously there is an influence of Human Resource Allocation but the paper focus only on 7 areas due to most highlighted issue currently almost all the projects are facing. This section describes the separate relation with Gap Analysis of Human Resource Allocation:-

\section{1) Scope Management}

The theme of project which describes the field, uniqueness and innovation of the project (De Jesus Nocêra 2012). The initiation is done by usually project manager or executive officer. It highly relates with allocated project manager who has signed for the initiation of project and documents the expected results. That results is going to be reflect at execution, controlling and closure process. Any mismanagement which highlights the responsibility of project manager or more rarely executive officer (Khalid at el, 2015).

2) Schedule Management

It is a major step of planning process which design the whole scheduling process utilizing all the resources including human allocation. Any single or more than single hurdles in scheduling produces negative impact will be a question mark on project manager and its concerned person for the schedule management. Any improvement in gap analysis brings edition in Human Resource Scheduling (Gransberg et al. 2012).

3) Cost Management

With respect to Gap Analysis, the most focused knowledge area where all the stakeholders have some directly or indirectly influence on it is known as cost management. Cost Estimation, Cost Budgeting and Cost Control all relies on the allocated persons from financial department. Gap Analysis occurrence will be questioned to financial team. Corruption Project Management (CPM) mostly found in this management which creates a huge gap in predicted analysis (Locatelli et al. 2017).

4) Quality Management

Quality is actually the outcome of project's products and services. Quality team is responsible for maintaining checklist of the qualities. The major objective depends on the quality of outcome. Gap Analysis is measured by the client or stakeholders with expectations. If there a huge gap analysis then audit will investigate and take quality team into custody (Agency for Healthcare Research and Quality 2012).

\section{5) Risk Management}

Risk Management is important for enterprise as it contains allocated human resource with skills of identifying and analysis of risk before it occurs. If risk is not properly identified and expands the gap analysis, then it will gets back to team as a responsible concern and arises the question about identification of risks (Carbone and Tippett 2004) (Khalid at el, 2015).

6) Procurement Management

Deliverables are initially defined in planning and executes accordingly by concerned team (Muhammad at el, 2015). Gap Analysis responsibility is assigned to the procurement team as the deliverables are executed under their supervisory (de Araújo, Alencar, and de Miranda Mota 2017).

7) Resource Management

Specifically, concerned with human resources and utilizing them into specific departments according to their skills and expertise (Fayaz a el, 2015). Sometimes it is difficult for HR person or Project Management to hire a reliable person (khalid at el, 2015). As sometimes, it seems quite easy on document that person is reliable for specific task as per prediction. But, sometimes, it goes in a wrong direction creating issues and later, it is found that actual skill doesn't match what is written on his Curriculum Vitae (Schuler and Jackson 2011). Training is necessary for updating their skills (Nadir Khan, 2012).

\subsection{Information Technology/ Engineering sectors}

In modern days, mostly projects are related to Information Technology and Engineering field. There lot of technical challenges usually faced by the stakeholders. The technical challenges not only effect the outcomes and services but also had an impact on timeline, costing, communication and risk (Nicholas 2018). Project Manager must sound as technical and having some engineering or IT related skills. Although, such kind of sectors includes technical knowledge, troubleshooting, repairing knowledge and integrating knowledge. Best technical project requires best and technically skillful human allocation such as engineers, developers, technicians. The major issue that reflects to create gap analysis in technical project is knowledge transfer. Currently many wellknown organizations faces such type of issues, experienced technical staff avoids to transfer the knowledge or 
his/her expertise to other in intention to mark his position permanently and to ensure organization has no other option except keeping him permanently (Argote, McEvily, and Reagans 2003). Such increases the gap analysis in human resource allocations as company becomes dependent on one person who individually founds difficulty in handling several projects at same duration.

\section{Methods for Gap Analysis Reduction}

Method to eliminate the hurdles, increases the gap analysis, cannot be done without controlling and execution. It can be done properly identifying and studying background of the defined scope. Human Resource Gap Analysis through scheduling can be minimized as concerned scheduling team should take feedback from controlling on regular intervals. Cost Management can be easily monitored through Cost Control in order to reduce gap analysis in financial team. Feedback is required for Quality control. But there are some methods which should not be pending to get minimized by controlling and monitoring stage. Procurement and Risk are generally planned accordingly by getting feedback of other knowledge areas or having past of similar project. But some minimization should be done at initiation stage preferably but at least up to planning stage. For Human Resource Gap Analysis, for itself Resource Management as well as for other knowledge areas, project manager should align a doubtful resource for a specific task proposed as Blind Dummy Task (BDT). The BDT is a task which is meaningless or useless for the specified project which is actually fake but pretends to be important according to the human resource assigned for it. It is blind because resource have no idea about the fakeness of the particular task. It is implemented to judge the skills and interest of human resource in the project. Figure 4 demonstrates the project of implementing data center for call center. Apart from all tasks, BDT can be anything as it can be useless for current project or perhaps get utilize in future or next task. But the main purpose is to identify the skills of person. In this method, the major precautionary step is not let the assigned person to get know about the fakeness of this task. It will demoralize him/her for the project. If passes the BDT then he can be the resource of original task of the project. The BDT team should be aligned and act as secretly not even letting other employee or stakeholders of the project.

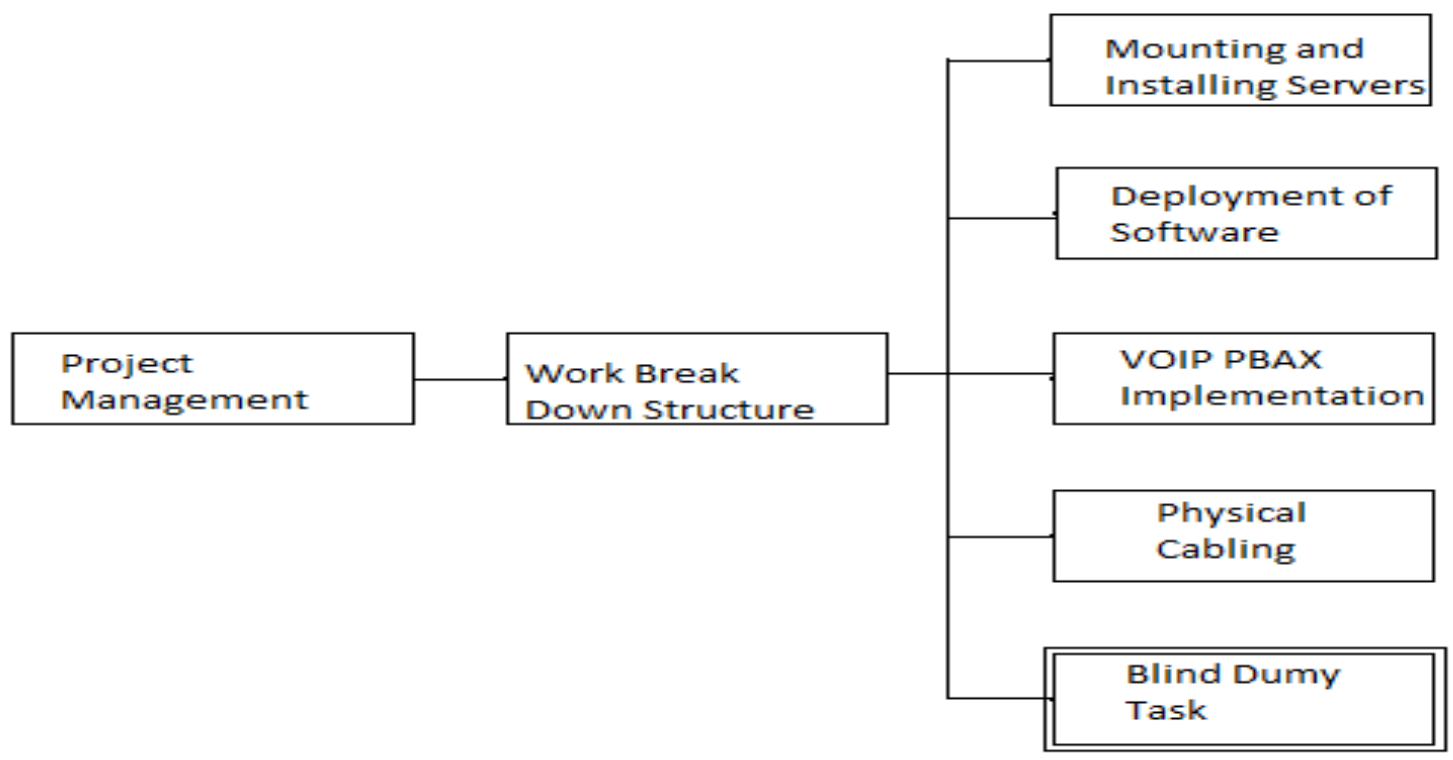

Figure 4 WBS for Installing Data Center for Call Center including BDT.

\section{Conclusion}

The new technique BDT has been proposed to judge the knowledge, skills and intention of aligned resource with the project. After finishing BDT, it can be utilized for future prospects. BDT should be stays secretive within executive officer, project manager and head of concerned department. The strategy will win the confidence of the employee. Organizations required to create friendly environment among employee to reduce lack of knowledge transfer. If it is not possible, organization should hire someone new and replica of the employee to have a backup in resource utilization. Gap Analysis not only controlled or minimized through controlling and planning stage, but also can be concluded or decided in initiation and planning stage. Anti-Corruption Measures (ACM) should be applied to remove CPM. 


\section{References:}

Agency for Healthcare Research and Quality. 2012. "The Epilepsies: The Diagnosis and Management of the Epilepsies in Adults and Children in Primary and Secondary Care." Guideline Summary NGC-8985.

de Araújo, Maria Creuza Borges, Luciana Hazin Alencar, and Caroline Maria de Miranda Mota. 2017. "Project Procurement Management: A Structured Literature Review." International Journal of Project Management.

Argote, Linda, Bill McEvily, and Ray Reagans. 2003. "Introduction to the Special Issue on Managing Knowledge in Organizations: Creating, Retaining, and Transferring Knowledge.” Management Science.

Carbone, Thomas A., and Donald D. Tippett. 2004. "Project Risk Management Using the Project Risk Fmea." EMJ - Engineering Management Journal.

Cobb, Anthony. 2014. "The Work Breakdown Structure." In Leading Project Teams: The Basics of Project Management and Team Leadership.

Fayaz at el. 2015. Increasing Performance through Assessed Training (A Human Recourse

Management Strategy), Journal of Resources Development and Management, ISSN 2422-8397 An International Peer-reviewed Journal Vol.7, 2015.

Freeman, R. Edward. 2015. Strategic Management: A Stakeholder Approach Strategic Management: A Stakeholder Approach.

Gransberg, Douglas D., Jennifer S. Shane, Kelly Strong, and Carla Lopez del Puerto. 2012. "Project Complexity Mapping in Five Dimensions for Complex Transportation Projects." Journal of Management in Engineering.

Hendriks, MHA, B Voeten, and L Kroep. 2002. "Human Resource Allocation in a Multi-Project R\&D Environment." International Journal of Project Management.

De Jesus Nocêra, Rosaldo. 2012. "Project Scope Management.” In The PMP® Certification Exam Study Guide,.

Khalid at el, 2015. Critical Success Factors for IT Projects in the Telecom Sector. Industrial

Engineering Letters. ISSN 2224-6096 (Paper) ISSN 2225-0581 (online) Vol.5, No.11, 2015.

Khalid at el, 2015. Relationship of Project Scope, Top Management Support, Skilled and

Competent Project Team and Project Manager's Leadership Qualities with Information Technology Projects. Industrial Engineering Letters ISSN 2224-6096 (Paper) ISSN 2225-0581 (online) Vol.5, No.11, 2015.

Lee, Chang. 2017. "Gap Analysis.” In Social Issues in the Workplace,

Locatelli, Giorgio, Giacomo Mariani, Tristano Sainati, and Marco Greco. 2017. "Corruption in Public Projects and Megaprojects: There Is an Elephant in the Room!” International Journal of Project Management.

Muhammad Ibrahim at el, 2015. Factors Influencing the Performance of Supply Chain

Management in Manufacturing Industry of Pakistan. Industrial Engineering Letters, ISSN 2224-6096 (Paper) ISSN 2225-0581 (online) Vol.5, No.8, 2015. Pp. 34-42.

Nicholas, John M. 2018. Project Management for Engineering, Business, and Technology Project Management for Engineering, Business, and Technology.

Nadir Khan at el, 2012, Impact of On-Job Training on Performance of Telecommunication

Industry, Journal of Social and Development Sciences, Vol. 3, No. 2, pp. 47-58, Feb 2012 (ISSN 2221-1152).

OECD/DAC. 2002. "Glossary of Key Terms in Evaluation and Results Based Management." Evaluation and Aid Effectiveness.

Økland, Andreas. 2015. “Gap Analysis for Incorporating Sustainability in Project Management.” In Procedia Computer Science,

PMI. 2013. Journal of Chemical Information and Modeling A Guide to the Project Management Body of Knowledge (PMBOK Guide).

Ridder, Hans Gerd, and Alina Mc Candless Baluch. 2017. "Strategic Human Resource Management." In The Nonprofit Human Resource Management Handbook: From Theory to Practice,.

Schuler, Randall S., and Susan E. Jackson. 2011. "Linking Competitive Strategies with Human Resource Management Practices." Academy of Management Executive. 